\title{
EFFECT OF SUMAC SEEDS POWDER ON SOME PERFORMANCES PARAMETER IN BROILER
}

\author{
BASHIR AL-BOSHI and RAID KUSSAIBATI \\ Department of Animal Production
}

Received: 8 February 2016; Accepted: 12 April 2016

\begin{abstract}
An experiment was carried out using (350) one day-old broiler non sexed chicks of commercial line available in Syria to investigate the effect of full sumac seeds powder and sumac seeds powder without nucleus on Live Body weight and Feed conversion ratio in Broilers at 42 days age. The birds were distributed into 7 the groups (50 / each). Rearing period was divided into 2 stages according to nutritional requirements mentioned in NRC, 1994. The First one from 1 to 21 days and the second from 22 to 42 days. Seven diets were prepared according to the group numbers including control group without any additive (First group). Full sumac seeds powder were added to diet with levels $(0.2 \%-0.4 \%-0.6 \%)$ respectively to groups $\left(2^{\text {nd }}-3^{\text {rd }}-4^{\text {th }}\right)$, and sumac seeds powder without nucleus were added to diet with levels $(0.2 \%-0.4 \%-0.6 \%)$ respectively to groups $\left(5^{\text {th }}-6^{\text {th }}-7^{\text {th }}\right)$ respectively. The results demonstrated an increase in average live body weight with high significant difference $(\mathrm{P} \leq 0.01)$ in the birds fed sumac seeds powder without nucleus in levels $(0.6-0.4) \%$ in groups $\left(7^{\text {th }}-6^{\text {th }}\right)$ respectively compared to control one ( $1^{\text {st }}$ group) superiority rates reached (7\%-5\%) respectively at 42 days age. Feed conversion ratio was better clearly by the addition of sumac seeds powder in both types compared to the control ( $1^{\text {st }}$ group birds) especially in the seventh group and the sixth group of birds of birds $(0.6 \%$ sumac seeds powder without nucleus) and ( $0.4 \%$ sumac seeds powder without nucleus) and the forth group of birds $(0.6 \%$ full sumac seeds powder) (1.72-1.75-1.78) respectively.
\end{abstract}

Key words: broiler, sumac, Live Body weight, Feed conversion ratio.

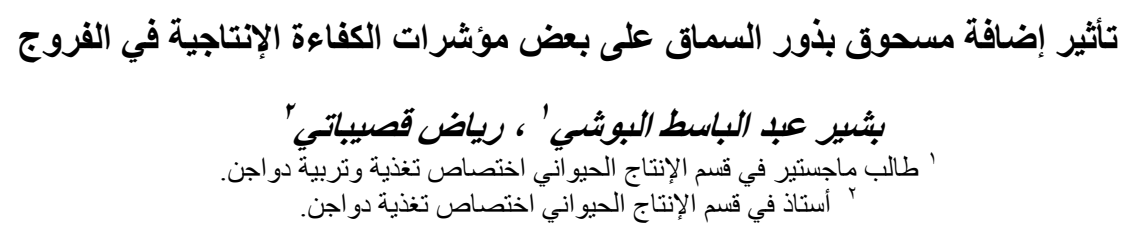

E-mail: bashir-alboshi@hotmail.com Assiut University web-site: www.aun.edu.eg

أجريت تجربة استخدم فيها 350 صوصاً من أحد هجن الفروج التجارية المنوفرة في سورية بعدر يوم واحد، كان الهدف من الدراسة

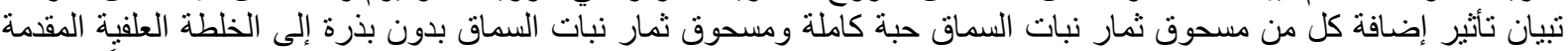

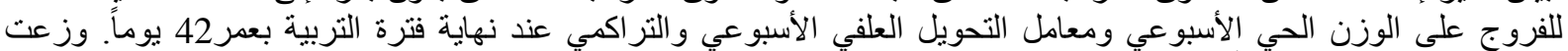

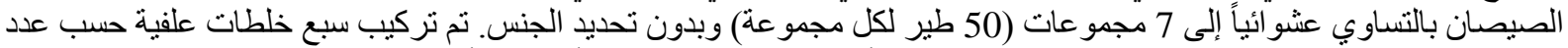

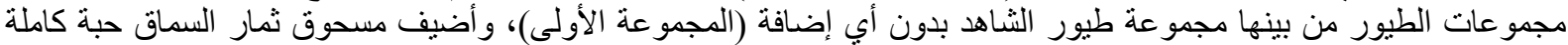

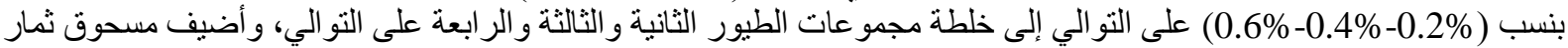
السماق بدون بذرة بنسب (0.2\%-0.2\%-0.4\%) على التو الي إلى خلطة مجموعات الطيور الخامسة و السادسة و السابعة على التو الي.

أظهرت النتائج زيادة في متوسط الوزن الحي في نهاية فترة التجربة وبفارق معنوي جداً (P>0.01) عند الطيور التي تتاولت خلطة

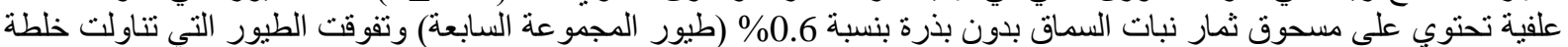

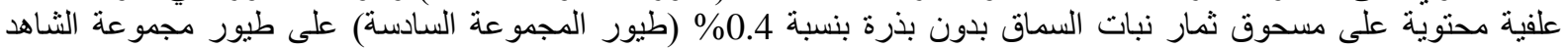

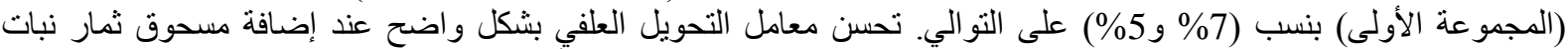

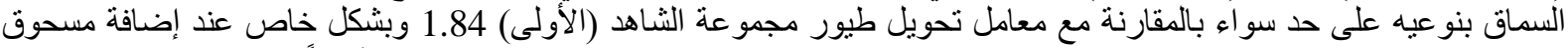

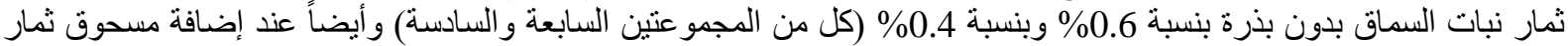

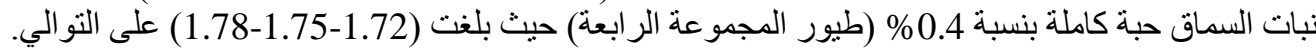

الكلمات المفتاحية : الفروج ـ السماق ـ الوزن الحي ـ معامل التحويل العلفي.

Corresponding author: Dr. BASHIR AL-BOSHI

E-mail address: bashir-alboshi@ @otmail.com

Present address: Department of Animal Production 


\section{INTRODUCTION}

\section{مقدمـة}

شههت صناعة الدواجن تطوراً واضحاً في السنوات الأخيرة وازداد الطلب على منتجاتها باعتبار ها أهم مصادر البروتين الحيو اني الإني

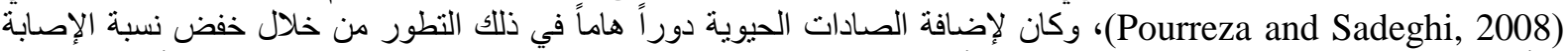

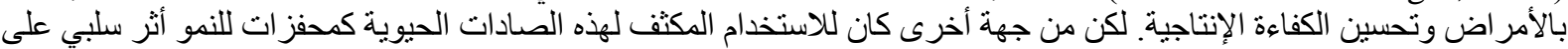

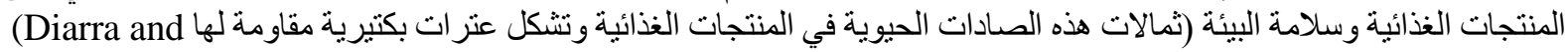

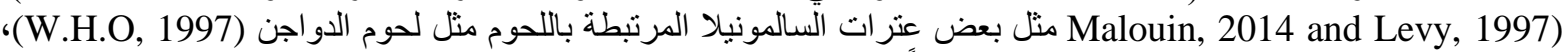

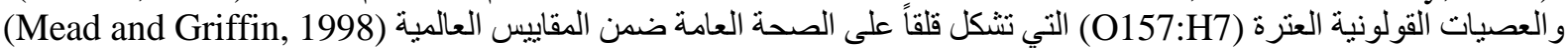

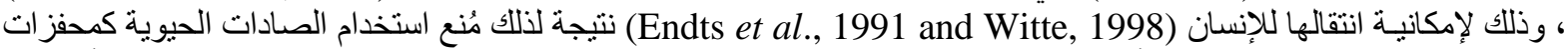
اللنمو في العديد من الدول المتقدمة لتأثير ها السلبي على كل من الإنسان و الحيوان (Wary and Davies, 2000).

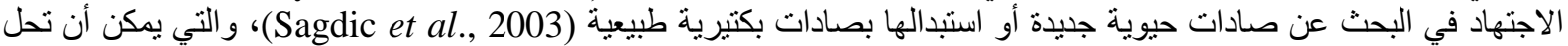

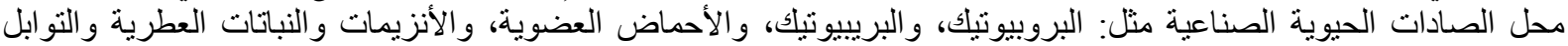
وخلاصاتها التي أثبت الكثير منها نجاعته في الحماية من بعض الأمر اض وتحسين الكفاءة الإنتاجية للحيوان (Greathead, 2003).

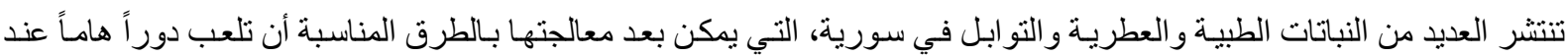

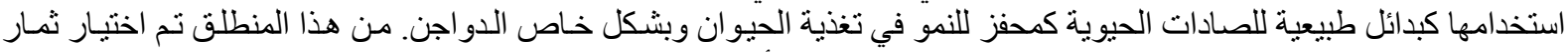

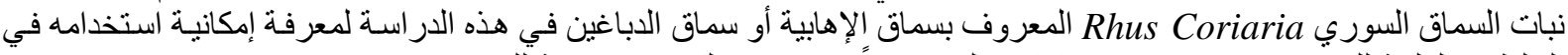

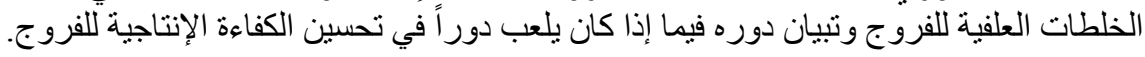

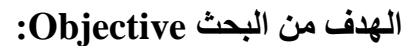
دراسة إمكانية إدخال مسحوق ثمار نبات السماق حبة كاملة أو القشرة مع اللب بدون البذان البذرة (النواة) في الخلطات العلفية المقدمة للفروج

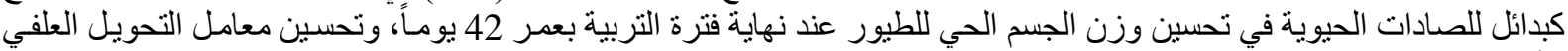
الأسبو عي و التر اكمي عند نهاية فترة التربية.

\section{MATERIALS AND METHODS المواد وطرائق البحث}

استخدم في التجربة ثلاث مئة وخمسين صوصاً من إحدى هجن الفروج التجاريـة بعدر يوم و احد دون التمييز بين الذكور و الإناث.

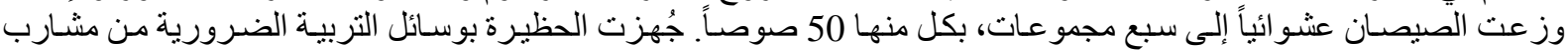

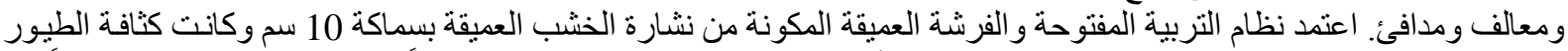

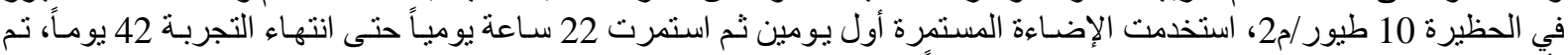
تأمين الحرارة والرطوبة و التهوية المناسبة للطيور وفقاً للمر احل العمرية.

تم الحصول على ثمار السماق كمنتج محلي مزروع في منطقة الساحل السوري ويباع في السوق المحلية على شكل عناقيد من الثمـار،

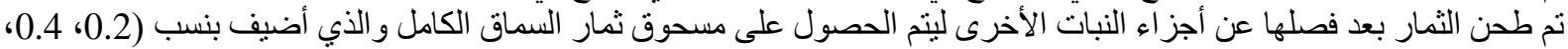

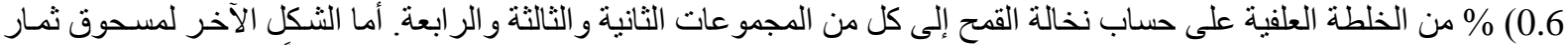

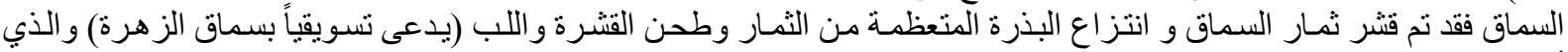

أضيف بنسب (0.2،0.4، 0.6) \% من الخلطة العلفية على حساب نخالة القمح لكل من المجمو عات الخامسة و السادسة و السابعة.

قكمت فترة التربية إلى مرحلتين: المرحلة الأولى (من عمر يوم حتى 21 يوم) و المرحلة الثانية (من عمر 22 يوم وحتى 42 يوم)، وكانت الخلطات العلفية على الثنكل النالي:

1- خلطة المجموعة الأولى: خلطة علفية حسب الاحتياجات الأمريكية (NRC,1994) لا تحتوي على ثمار السماق.

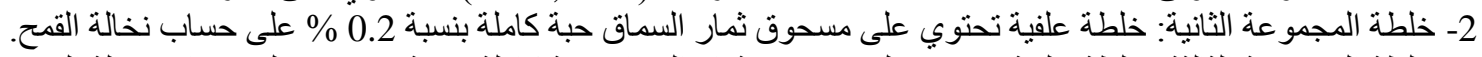

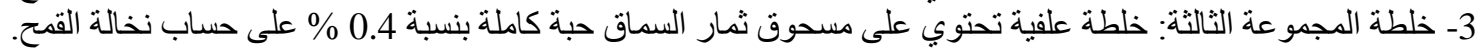

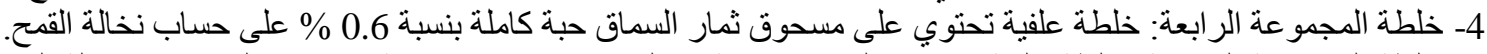

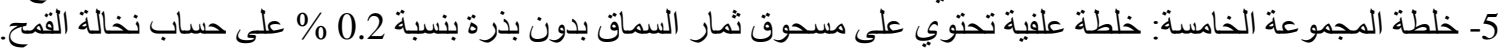

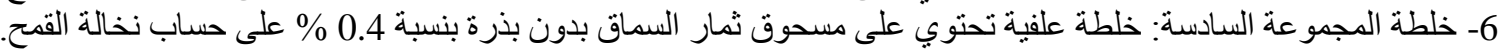
7- خلطة المجمو عة السابعة: خلطة علفية تحنوي على مسحوق ثمار السماق بدون بذرة بنسبة 0.6 \% على حساب نخالة القمح.

$$
\text { تركيب الخلطات العلفية وتحليل قيمها موضح بالجدول رقم ( (1) و الجدول رقم (؟) ). }
$$
فيما يظهر الجدول رقم (r) برنامج التحصين المستخدم للطيور. 


\begin{tabular}{|c|c|c|c|}
\hline الثانية & الأولى & المرحلة العلفية & \\
\hline (42-22) يوم & ) & 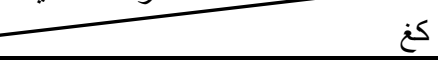 & المكونات \\
\hline 615 & 555 & ذرة صفر اء & \\
\hline 313.5 & 368 & كسبة فول الصويا (44\% بروتين) & \\
\hline 6 & 6 & نخالة القمح & \\
\hline 27 & 26 & زيت فول الصويا & \\
\hline 16 & 18 & فوسفات ثنائية الكالسيوم & \\
\hline 12 & 13.5 & حجر كلسي & \\
\hline 1.5 & 2 & لايسين حر & \\
\hline 1 & 2 & مثيونين حر & \\
\hline 1 & 1 & خلطة فيتامينات** & \\
\hline 1 & 1 & خلطة معادن** & \\
\hline 1 & 1 & كلوريد الكولين & \\
\hline 1.8 & 2.6 & ملح طعام & \\
\hline 2.7 & 3.4 & بيكربونات الصوديوم (كربو لا) & \\
\hline 0.5 & 0.5 & مضاد كو كسيديا & \\
\hline 1000 & 1000 & المجموع & \\
\hline
\end{tabular}

*تم إدخال مسحوق ثمار السماق على حساب نخالة القمح.

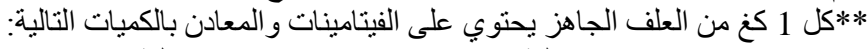

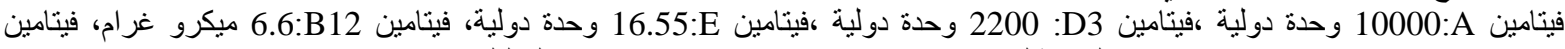

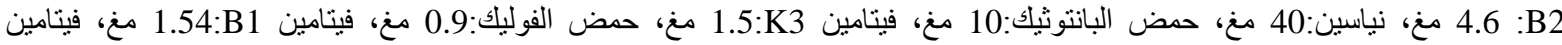

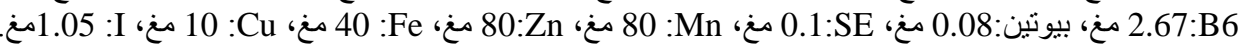

جدول رقم ؟َ: القيم الغذائية للخلطات العلفية المستخدمة في التجربة.

\begin{tabular}{|c|c|c|c|}
\hline & الأولى & المرحلة & \\
\hline (42-22) يوم & (21-1) يوم & & المكونات \\
\hline 3028 & 2945 & الطاقة القابلة للتمثيل ك ك/كغ & \\
\hline 19.07 & 21.08 & بروتين\%\% & \\
\hline 158.80 & 139.69 & $* \mathrm{c} / \mathrm{p}$ & \\
\hline 1.13 & 1.29 & لايسين\%\% & \\
\hline 0.41 & 0.53 & مثيونين \% & \\
\hline 0.73 & 0.87 & مثيونين+سيستين\%\% & \\
\hline 0.91 & 1.03 & كالسيوم\%\% & \\
\hline 0.43 & 0.47 & فوسفور متاح\% & \\
\hline 0.16 & 0.21 & صوديوم \% & \\
\hline 0.17 & 0.21 & كلور \% & \\
\hline 2.89 & 2.73 & حمض اللينولييك\%\% & \\
\hline 3.62 & 3.86 & الألياف\% & \\
\hline
\end{tabular}

نسبة الطاقة إلى البروتين في الخلطة العلفية. c/p

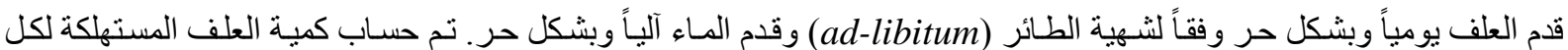

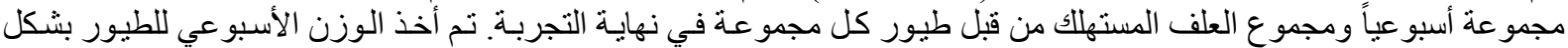

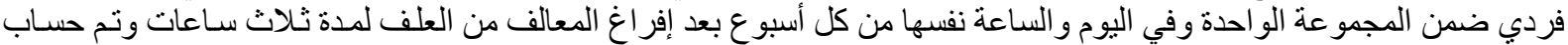
معامل التحويل العلفي الأسبو عي والتنر اكمي بالعلاقات التالية:

معامل التحويل العلفي الأسبو عي = كمية العلف المستهلكة أسبو عياً بالغر ام \الزيادة الوزنية في الأسبوع بالغر ام.

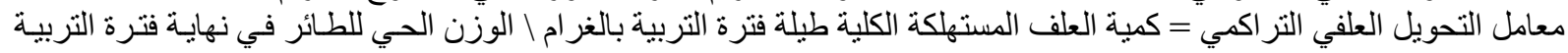
بعمر 42 يوم بالغر ام. 


\begin{tabular}{|c|c|c|}
\hline 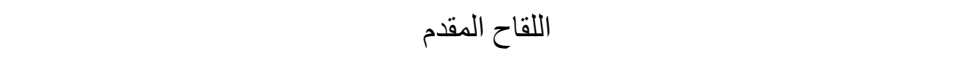 & طريقة إعطاء اللقاح & 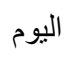 \\
\hline مرض التهاب الشعب الهو ائية IB عترة Ma5 مرض النيوكاسل ND عترة Clone30 & 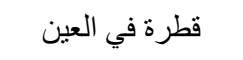 & 1 \\
\hline Dرض التهاب الجر اب المعدي (الجامبورو) IBD عترة D78 & 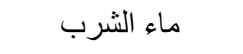 & 10 \\
\hline مرض النيوكاسل ND عترة Clone30 & 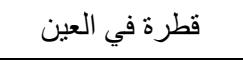 & (1) \\
\hline مرض النيوكاسل ND عترة Clone30 & قطرة في العين & ro \\
\hline
\end{tabular}

التحليل الإحصائي Statistical analysis:

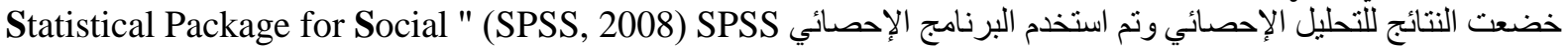
"Sciences

الاتجـاه "One - Way ANOVA) "One - Way Analysis of Variance).

\section{RESULTS AND DISCUSSION \\ النتائســـج والمناقشــــة}

ا ـ متوسط الوزن الحي الأسبوعي:

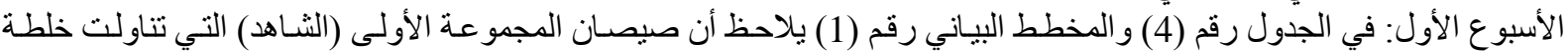
علفية تقليدية تفوقت بشكل معنوي عند (P)

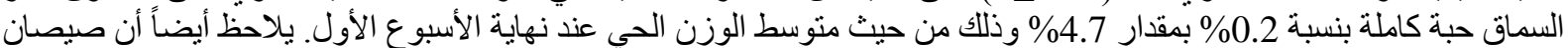

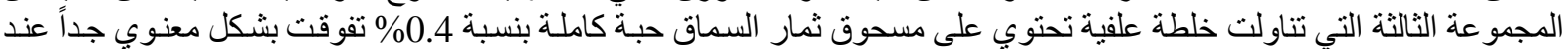

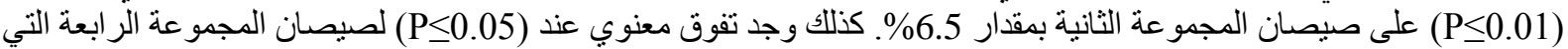

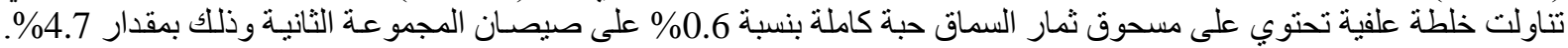

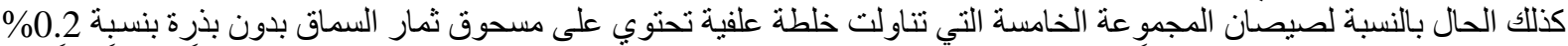

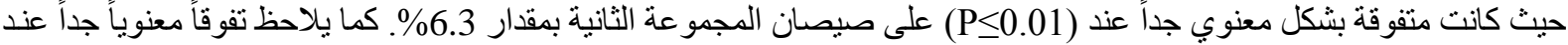

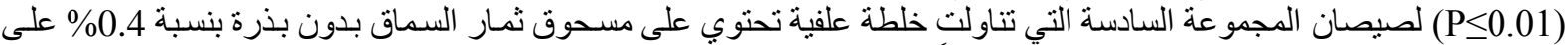

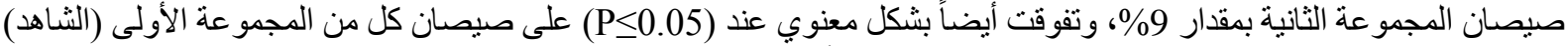

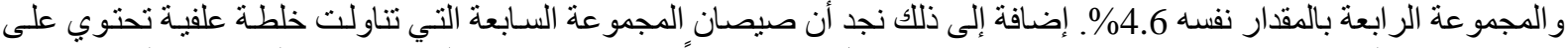

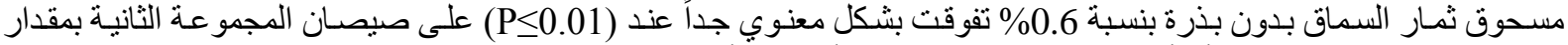

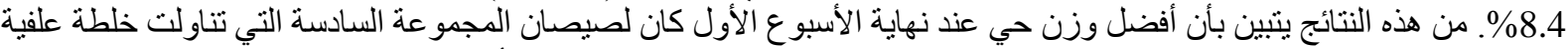

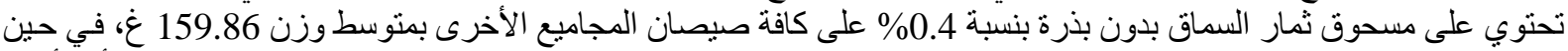

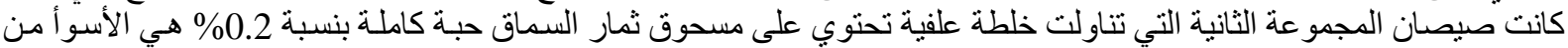
حيث منوسط الوزن 145.41 غ عند نهاية الأسبوع الأول.

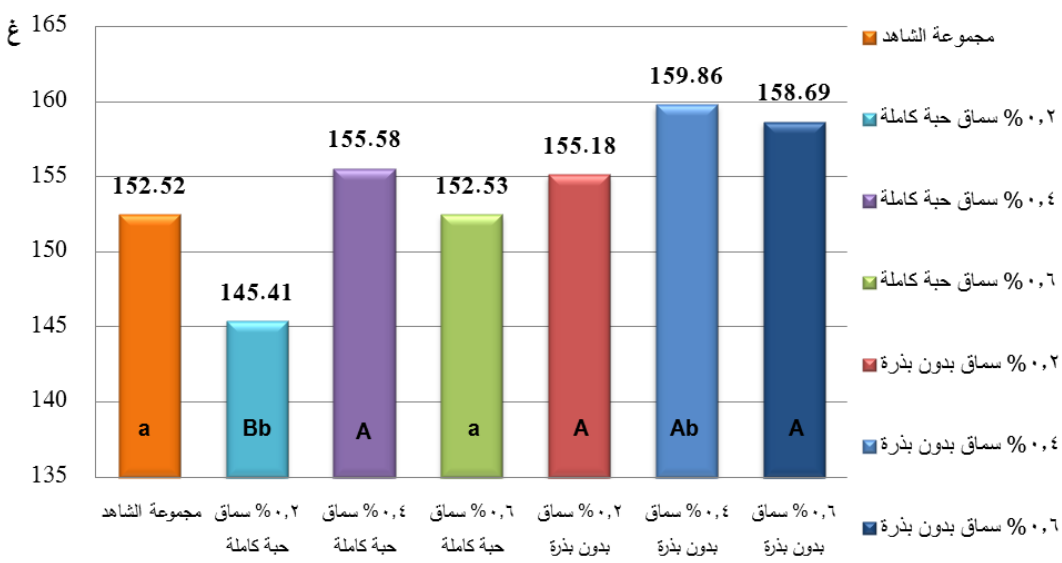

مخطط رقم (1) : متوسط الوزن الحي للصيصان عند نهاية الأسبوع الأول (غ)

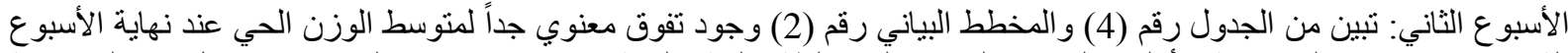

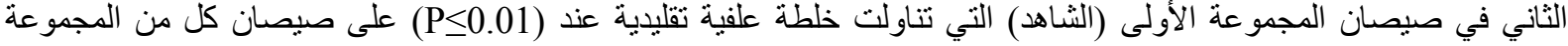

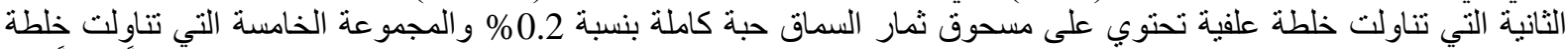
علفية تحنوي على مسحوق ثمار السماق بدون بذرة بنسبة 0.2\% بمقدار 9.3\% و 


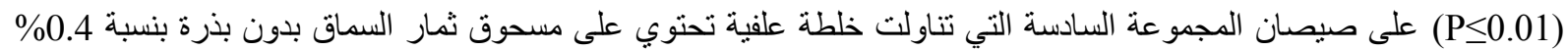

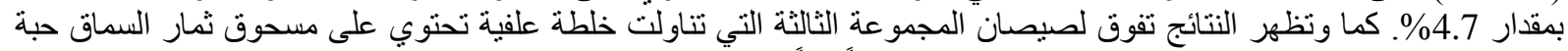

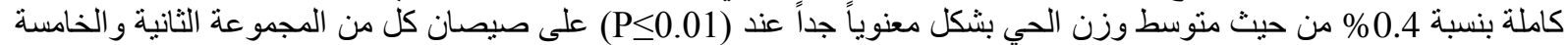

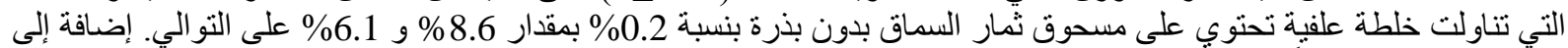

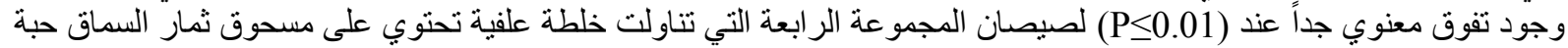

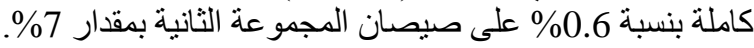

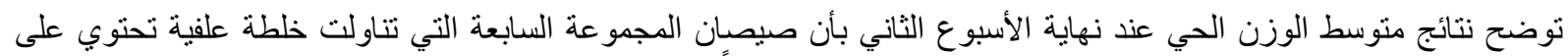

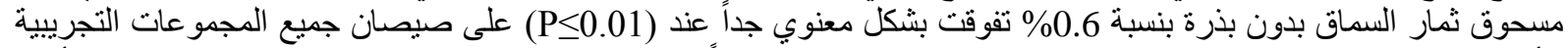

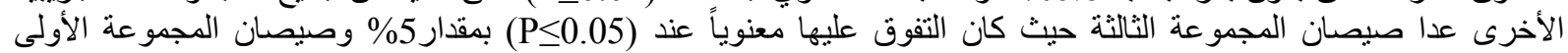

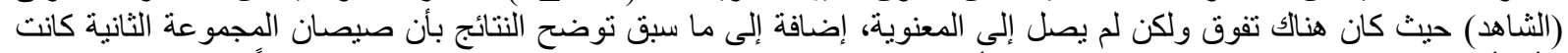

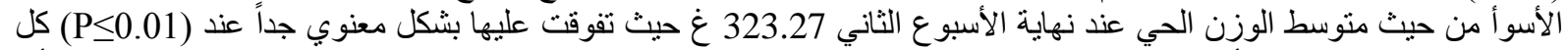

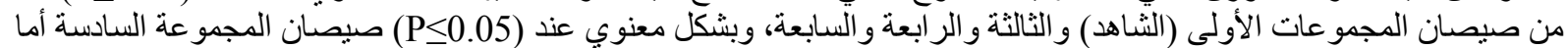

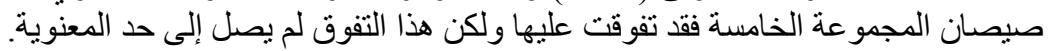

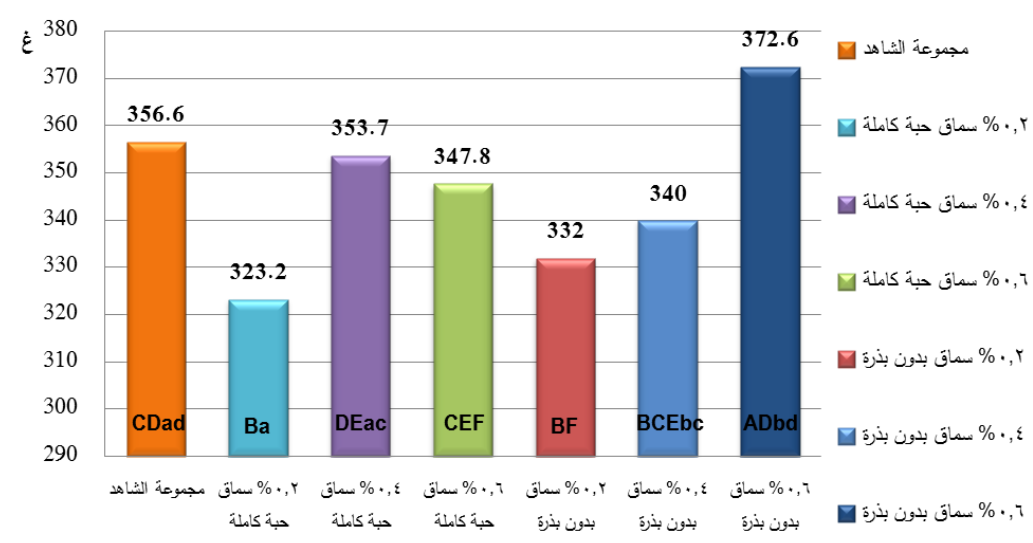

مخطط رقم (2) : منوسط الوزن الحي للصيصان عند نهاية الأسبوع الثاني (غ)

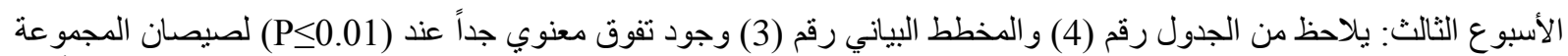

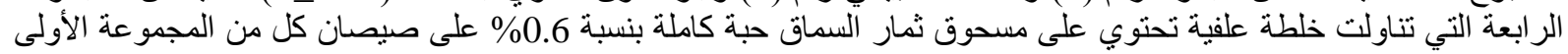

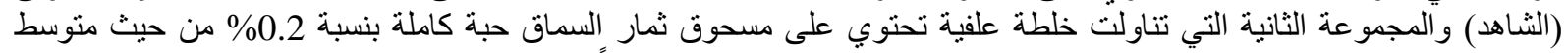

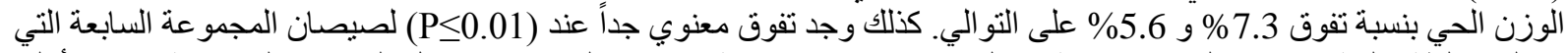

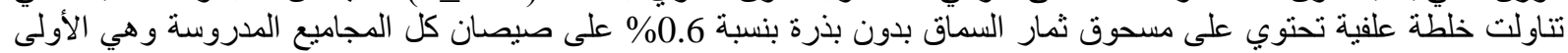

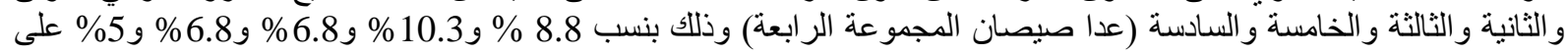
النو الي.

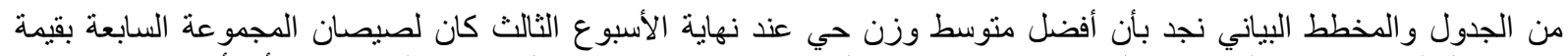

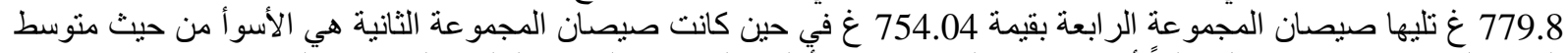

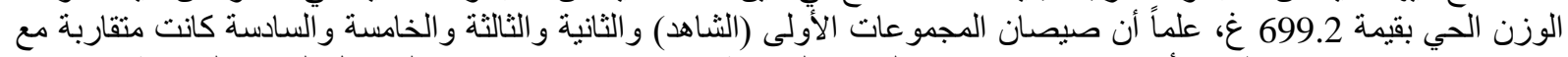

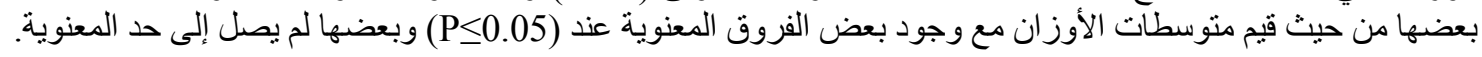

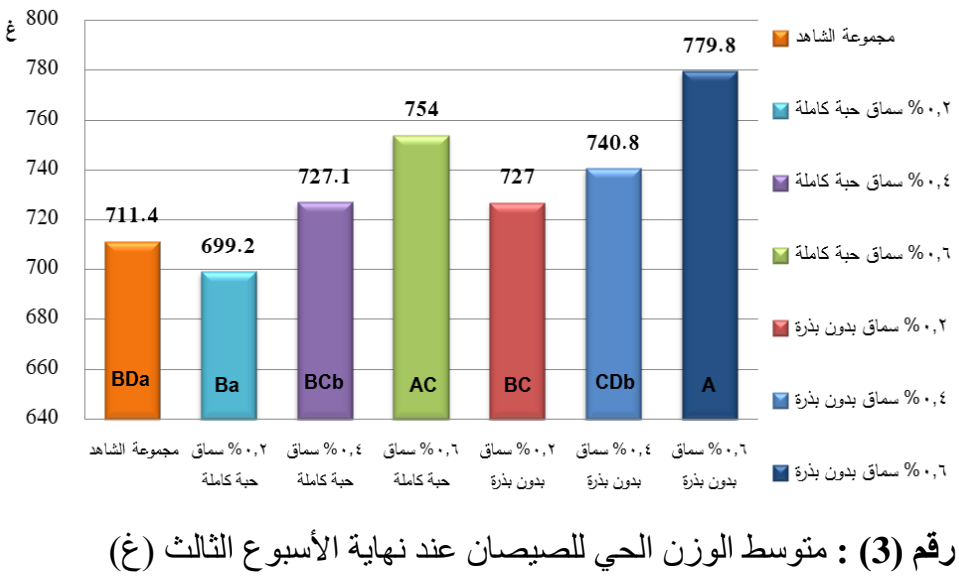




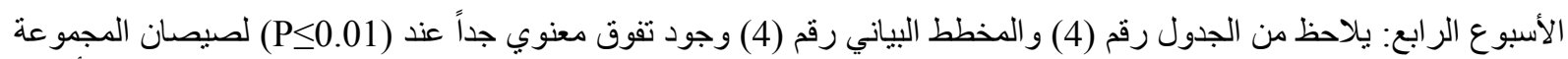

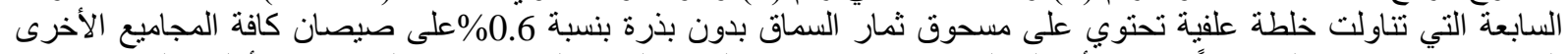

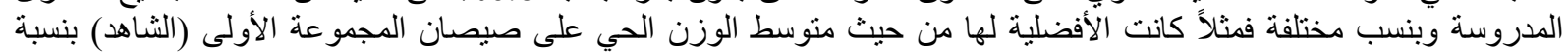

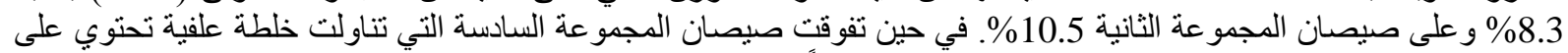

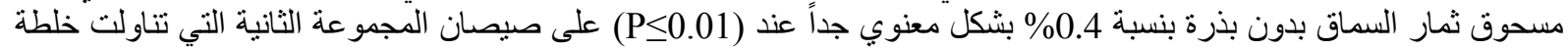

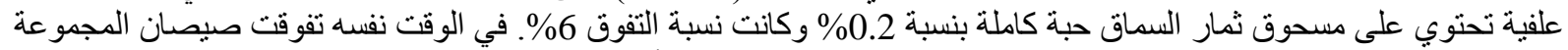

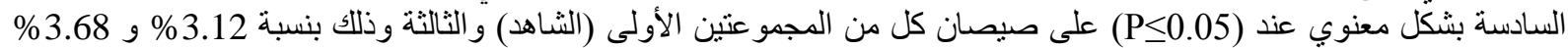
على التو الي.

كذلك وجد تفوق معنوي عند (P<0.05) لصيصان المجموعة الخامسة التي تناولت خلطة علفية تحتوي على مسحوق ثمار السماق

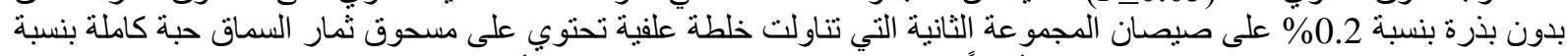

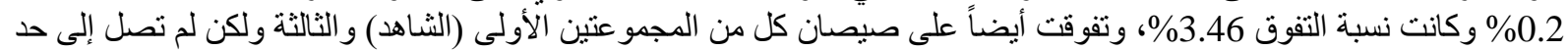

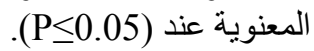

يلاحظ أيضاً أن صيصان المجموعة الرابعة التي تتاولت خلطة علفية تحتوي على مسحوق ثمار السماق حبة كاملة بنسبة 0.6\%

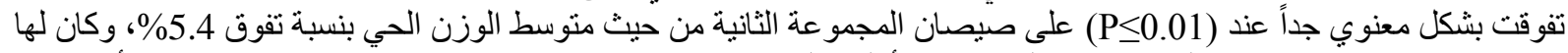

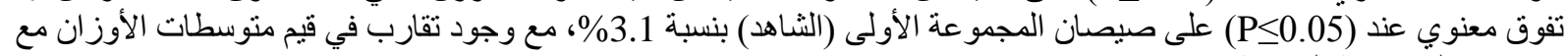
صيصان المجمو عة السادسة.

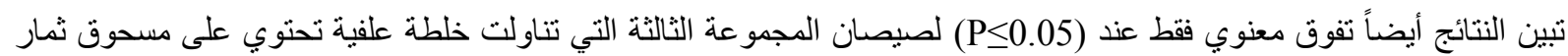

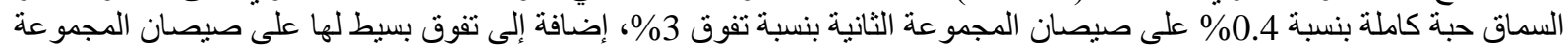
الأولى (الثاهد) لم تصل إلى حد المعنوية عند (P<0.05).

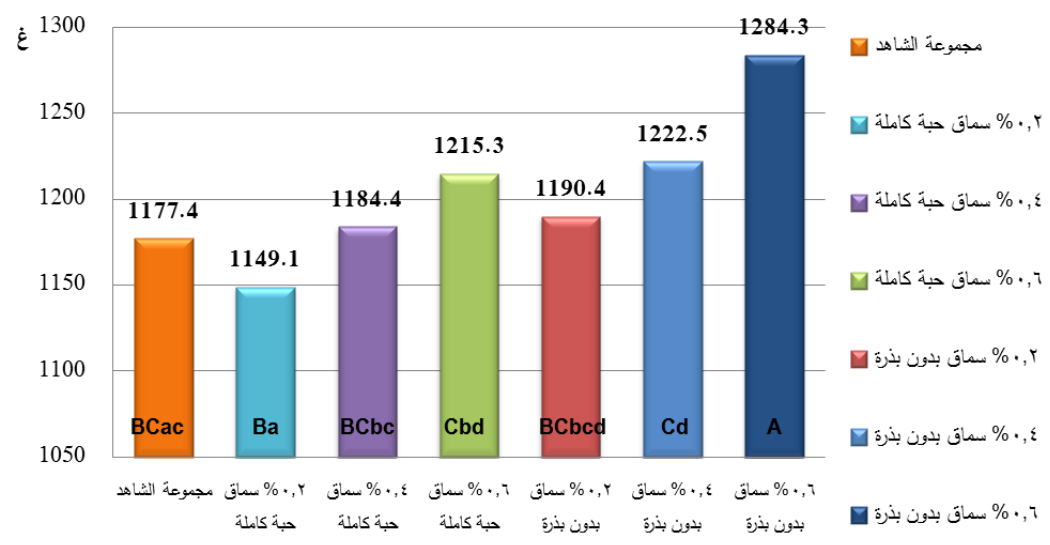

مخطط رقم (4) : منوسط الوزن الحي للصيصان عند نهاية الأسبوع الرابع (غ)

الأسبوع الخامس: يلاحظ من الجدول رقم (4) و المخطط البياني رقم (5) استمر ار تفوق طيور المجمو عة السابعة التي تناولت خلطة

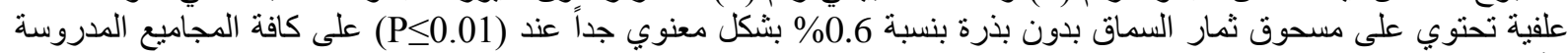

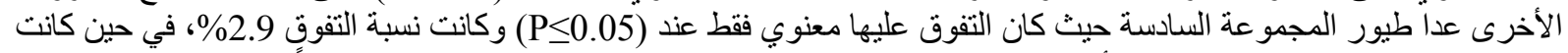

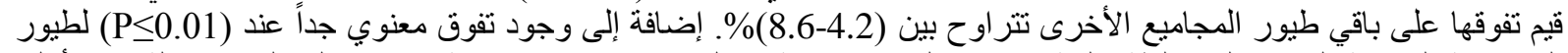

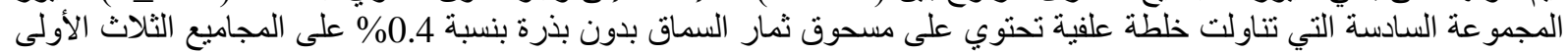

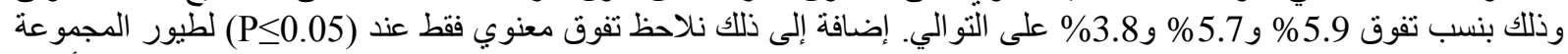

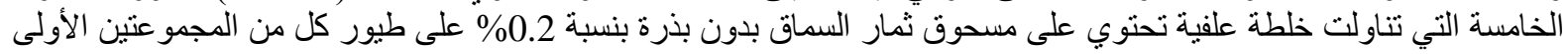

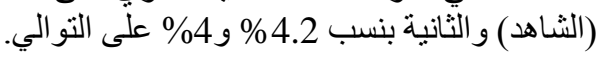

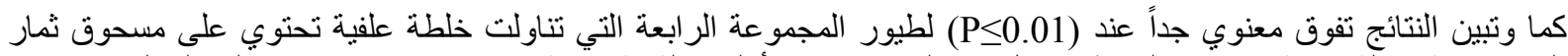

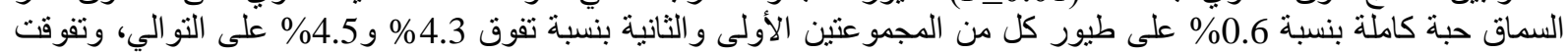

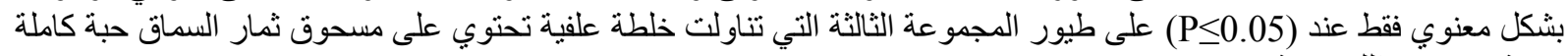

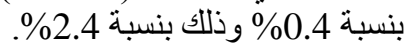




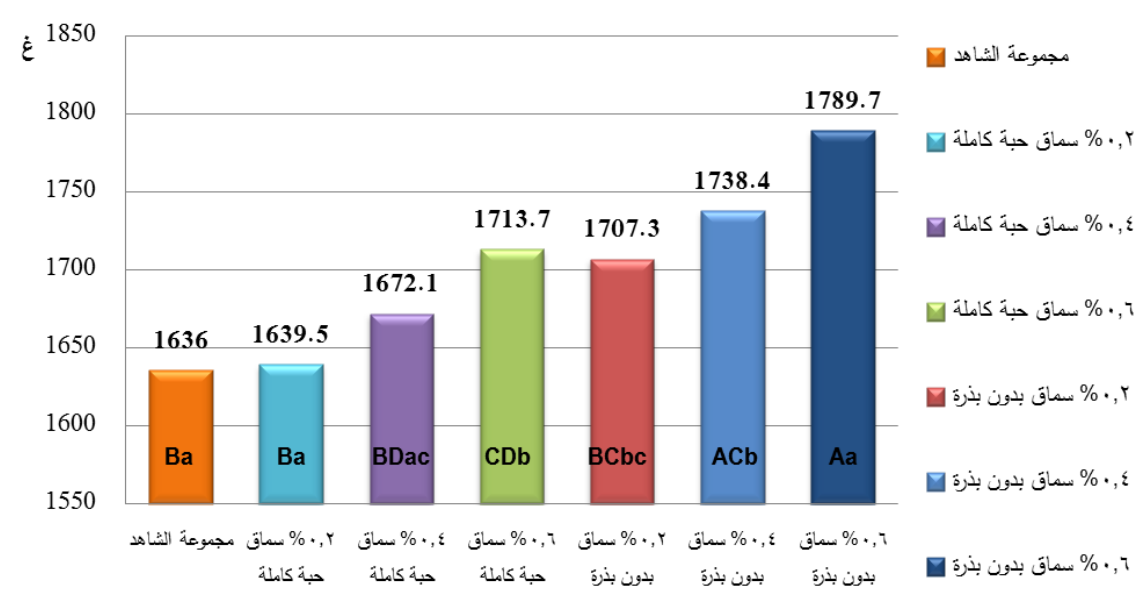

مخطط رقم (5) : منوسط الوزن الحي للصبصان عند نهاية الأسبوع الخامس (غ)

الأسبو ع السادس: يلاحظ من الجدول رقم (4) و المخطط البياني رقم (6) استمر ار تفوق طيور المجموعة السابعة التي تناولت خلطة

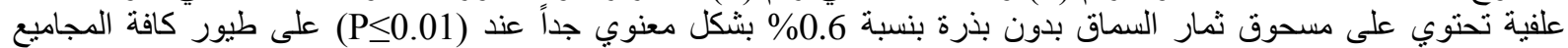

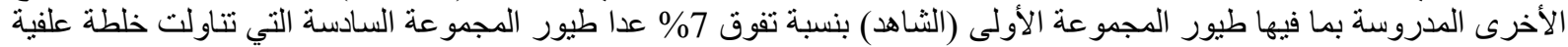

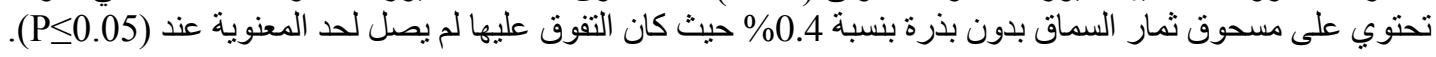

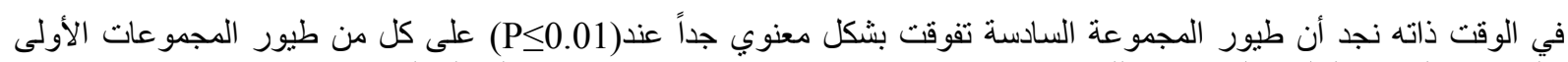

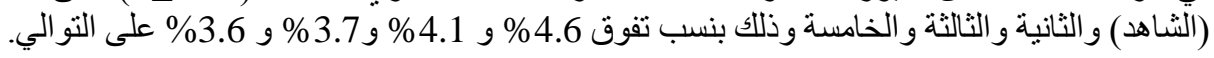

في حين نلاحظ تقارب كبير بين منوسطات الأوزان طيور المجموعة الرابعة التي تناولت خلطة علفية تحتوي على مسحوق ثمار

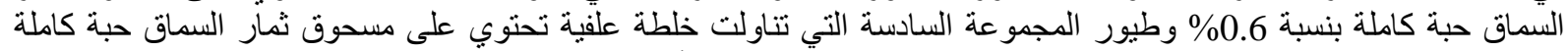
بنسبة 0.4\%، إضافة إلى زوال الفروق المعنوية بين المجموعات الخمس الأولى مع وجود تفوق لطيور المجمو عة الرئ الرابعة عنهم ولكن لم يصل هذا التفوق إلى حد المعنوية.

من الجدول رقم (4) و المخطط البياني رقم (6) نلاحظ أن أفضل متوسط وزن حي عند نهاية فترة التربية بعمر 42 يوماً كان لطيور

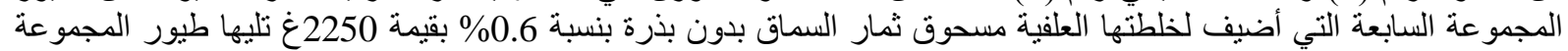

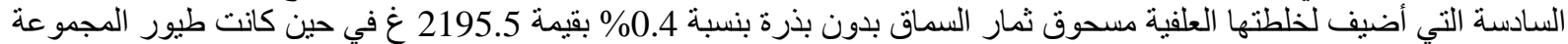

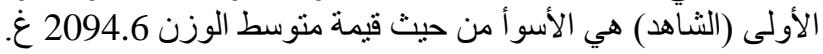

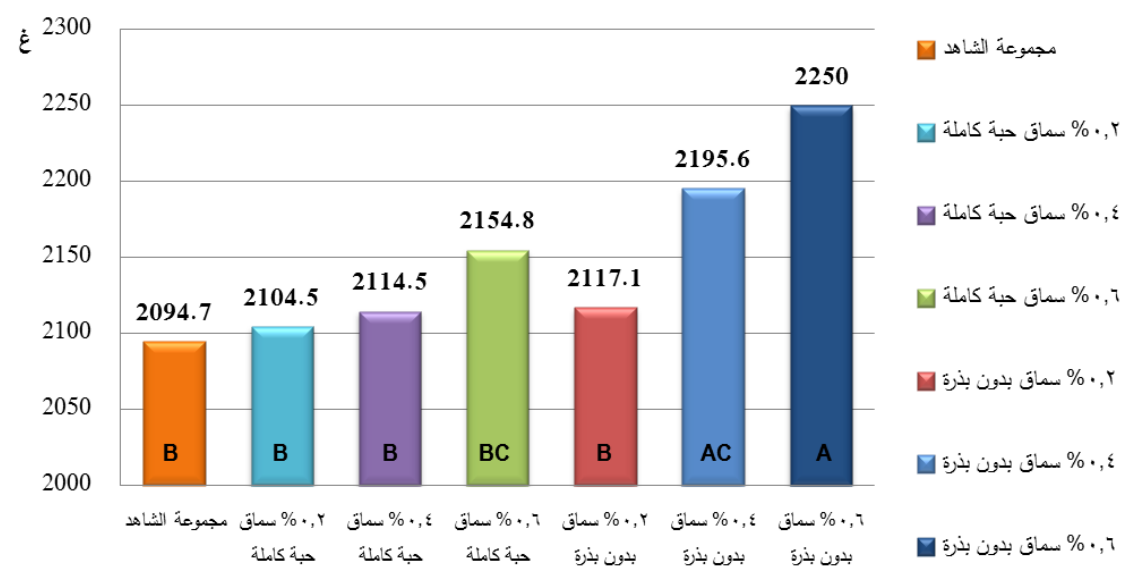

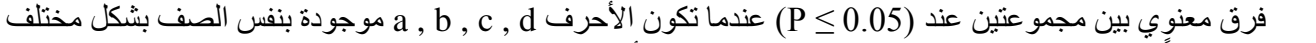

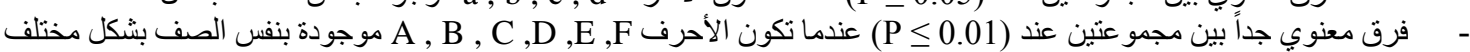

مخطط رقم (6) : منوسط الوزن الحي للطيور عند نهاية الأسبوع السادس (غ) 
جدول رقم ؛ : متوسط الوزن الحي الأسبو عي للطيور (غ) والانحر اف المعياري.

\begin{tabular}{|c|c|c|c|c|c|c|c|}
\hline المجموعة (v) & المجموعة (7) & المجموعة (0) & المجموعة (؛) & المجموعة (r) & المجموعة (r) & المجموعة ( ) & المجموعات \\
\hline باون بذرة 0.6 سماق & ب \% بون بذرة 0.4 سماق & باون بذرة & \% 0.6 سمة كاملة & \% 0.4 سماقة كاملة & \% 0.20 سماق كاملة & الشاها بدون & الأسابيع \\
\hline A & $\mathrm{Ab}$ & A & $\mathrm{a}$ & $\mathrm{A}$ & $\mathrm{Bb}$ & $\mathrm{a}$ & الأول \\
\hline 158.69 & 159.86 & 155.18 & 152.53 & 155.58 & 145.41 & 152.52 & \\
\hline $14.67 \pm$ & $15.19 \pm$ & $15.12 \pm$ & $17.42 \pm$ & $15.89 \pm$ & $12.42 \pm$ & $18.05 \pm$ & \\
\hline ADbd & BCEbc & $\mathrm{BF}$ & CEF & DEac & $\mathrm{Ba}$ & $\mathrm{CDad}$ & الثانى \\
\hline 372.57 & 339.84 & 331.96 & 347.75 & 353.70 & 323.27 & 356.59 & \\
\hline $40.40 \pm$ & $37.48 \pm$ & $35.51 \pm$ & $44.49 \pm$ & $43.84 \pm$ & $32.51 \pm$ & $47.27 \pm$ & \\
\hline A & $\mathrm{CDb}$ & $\mathrm{BC}$ & $\mathrm{AC}$ & $\mathrm{Bcb}$ & $\mathrm{Ba}$ & $\mathrm{BDa}$ & الثالث \\
\hline 779.82 & 740.75 & 727.02 & 754.02 & 727.08 & 699.23 & 711.39 & \\
\hline $73.40 \pm$ & $75.51 \pm$ & $77.72 \pm$ & $66.77 \pm$ & $71.71 \pm$ & $62.71 \pm$ & $53.85 \pm$ & \\
\hline A & $\mathrm{Cd}$ & BCbcd & Cbd & $\mathrm{BCbc}$ & $\overline{\mathrm{Ba}}$ & $\overline{\mathrm{BCac}}$ & الرابع \\
\hline 1284.31 & 1222.51 & 1190.41 & 1215.30 & 1184.37 & 1149.13 & 1177.43 & \\
\hline $98.03 \pm$ & $84.46 \pm$ & $90.66 \pm$ & $73.90 \pm$ & $80.24 \pm$ & $72.07 \pm$ & $91.54 \pm$ & \\
\hline $\mathrm{Aa}$ & $\mathrm{ACb}$ & $\mathrm{BCbc}$ & $\mathrm{CDb}$ & BDac & $\mathrm{Ba}$ & $\mathrm{Ba}$ & الخامس \\
\hline 1789.74 & 1738.39 & 1707.28 & 1713.67 & 1672.11 & 1639.50 & 1635.91 & \\
\hline $102.98 \pm$ & $94.66 \pm$ & $101.40 \pm$ & $124.26 \pm$ & $155.58 \pm$ & $115.49 \pm$ & $150.30 \pm$ & \\
\hline A & $\mathrm{AC}$ & B & $\mathrm{BC}$ & B & B & B & السادس \\
\hline 2250.02 & 2195.57 & 2117.10 & 2154.78 & 2114.50 & 2104.51 & 2094.67 & \\
\hline $142.56 \pm$ & $128.76 \pm$ & $168.65 \pm$ & $144.94 \pm$ & $162.52 \pm$ & $137.50 \pm$ & $138.05 \pm$ & \\
\hline
\end{tabular}

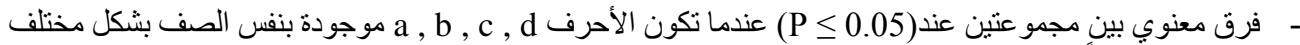

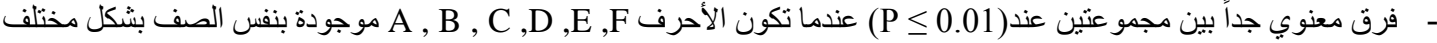

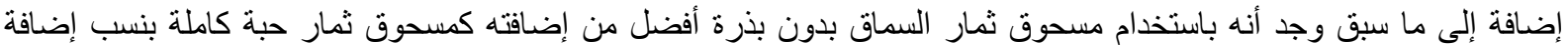

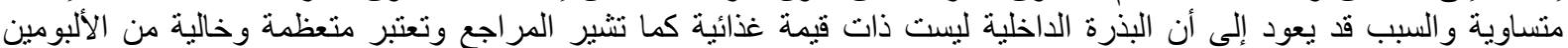

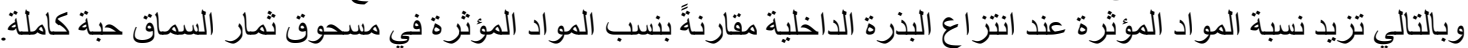

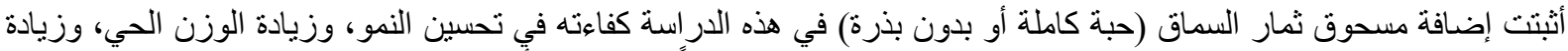

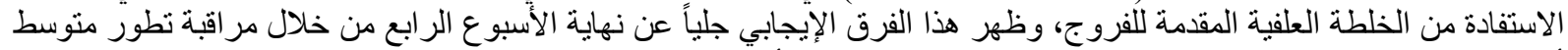

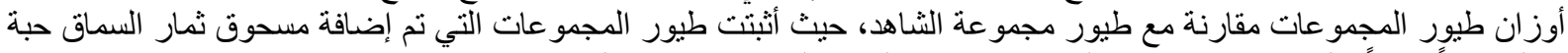

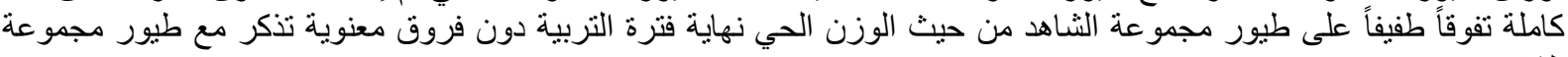

الثاهد.

أما بالنسبة لطيور المجموعات التي أضيف لخلطتها العلفية مسحوق ثمار السماق بدون بذرة فقد تفوقت بشكل واضح من حيث الوزن النها

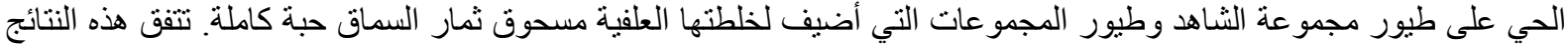

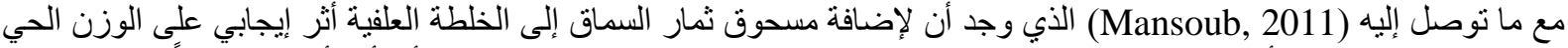

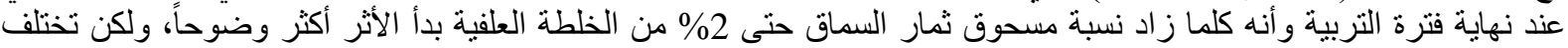

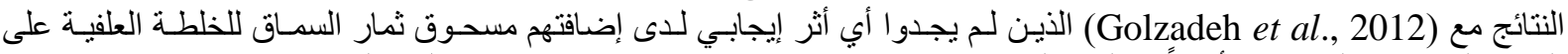

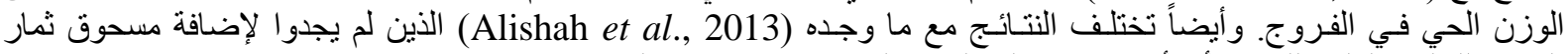
السماق للخلّة العلفية للفروج أي أثر إيجابي على الوزن الحي عند نهاية فترة التربية.

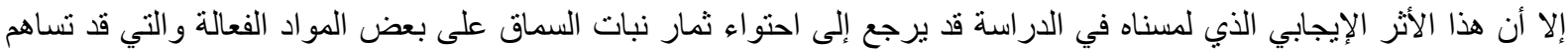

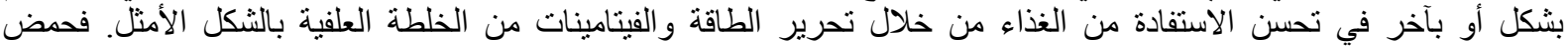

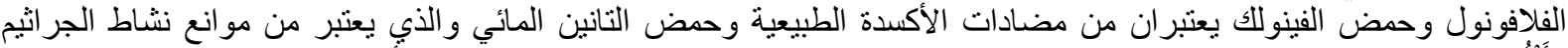

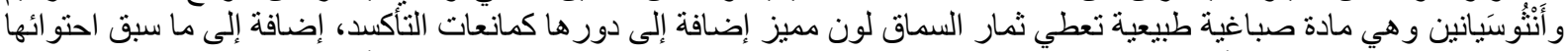

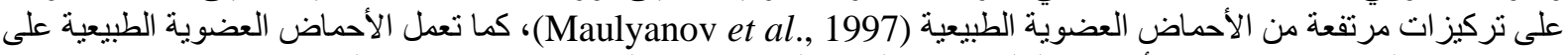

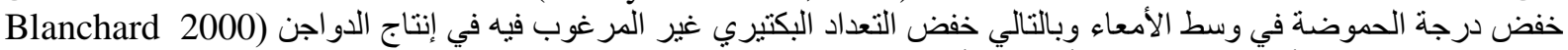
and Wright,

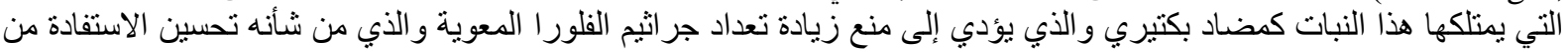


r ـ معامل التحويل العلفي الأسبوعي والتراكمي لطيور المجموعات المدروسة خلال الفترة التربية:

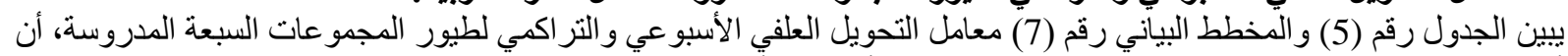

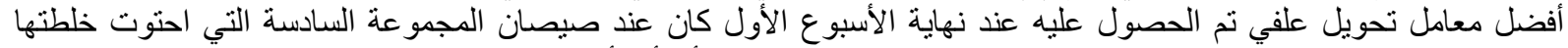

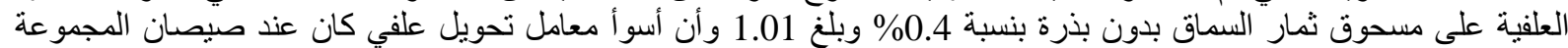

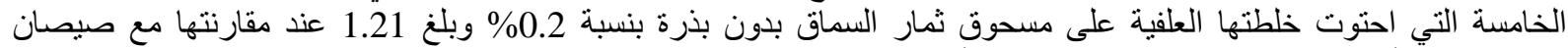
المجموعات الأخرى بما فيها صيصان المجمو عة الأولى (الثناهد).

وتظهر النتائج أيضاً عند نهاية الأسبوع الثاني أن صبصان المجمو عة السابعة كانت الأفضل من حيث معامل التحويل العلفي وبلغ 1.20 في حين كانت صيصان المجموعة الثانية هي الأسو أ من حيث معامل التحويل العلفي وبلغ الأن 1.43.

أما عند نهاية الأسبوع الثالث كان أفضل معامل تحويل علفي عند صيصان المجمو عة الر ابعة التي احتوت خلطتها العلفية على مسحوق

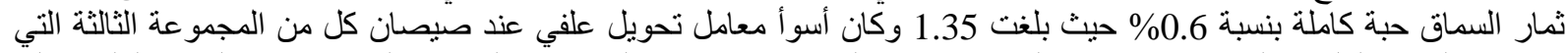

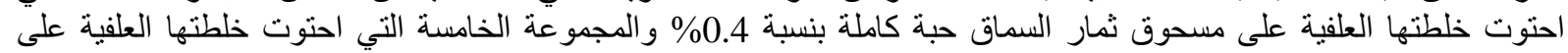

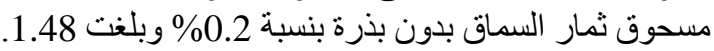

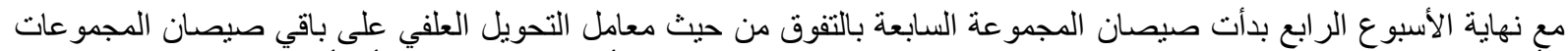

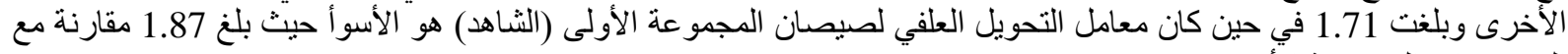

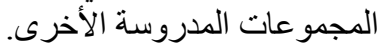

تقاربت قيم معامل التحويل عند نهاية الأسبوع الخامس بين طيور المجموعات السبعة الددروسة مع تفوق لطيور الهجموعة السادسة

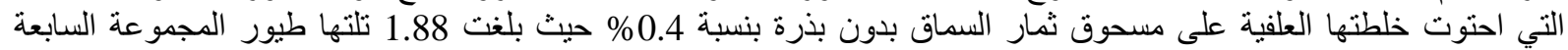
والرابعة وبلغت قيم معامل تحويلها 1.89 وكانت أسوأ قيمة لمعامل التحويل العلفي بالنسبة لطيور المجموعة الأولى (الثاهد) و وبلغت 2.07.

استمرت طيور المجموعة السابعة عند نهاية الأسبوع السادس بالتفوق من حيث معامل التحويل العلفي على باقي طيور المجموعات

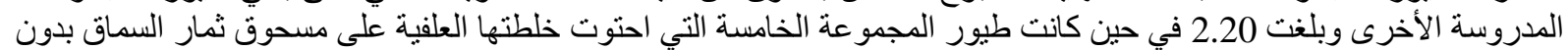

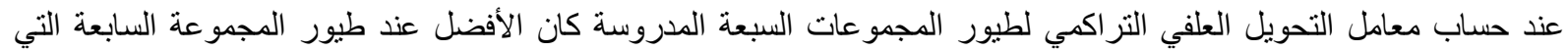

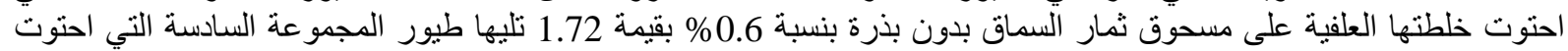

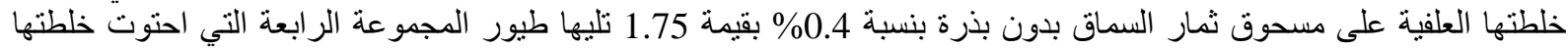

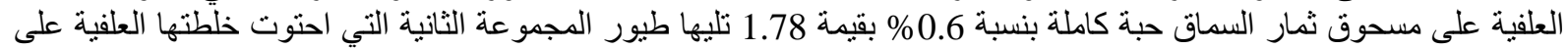

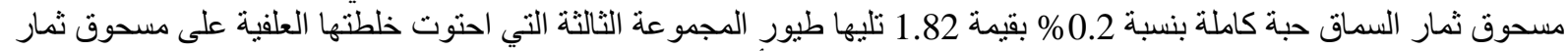

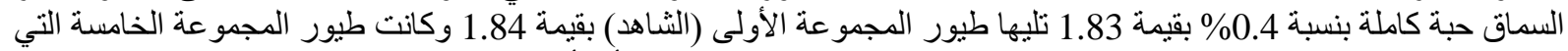
احتوت خلطتها العلفية على مسحوق ثمار السماق بدون بذرة بنسبة 0.2\% هي الأسو أ من حيث معامل التحويل العلفي التراكي بقيمة

مما سبق نجد أن إضافة مسحوق ثمار السماق بدون بذرة بنسب لا تقل عن 0.4\% من الخلطة العلفية المقدمة للفروج حسن من معامل

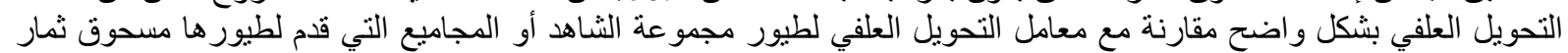

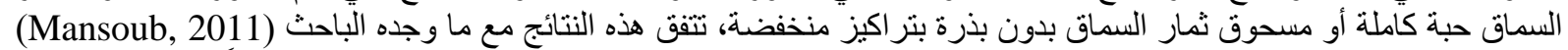

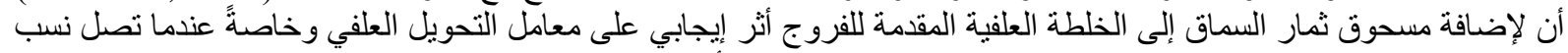

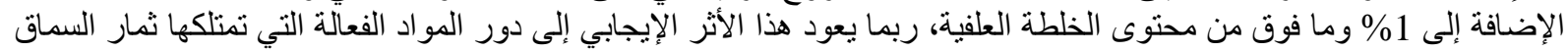

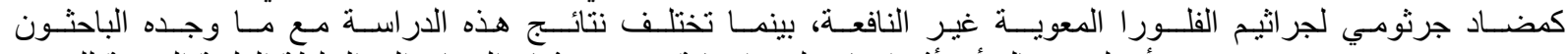
(Golzadeh et al., 2012)

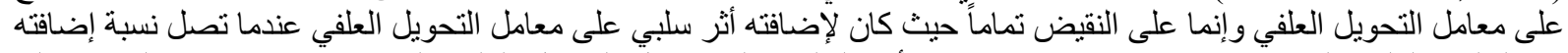

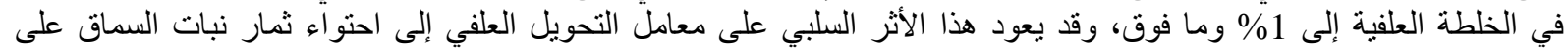

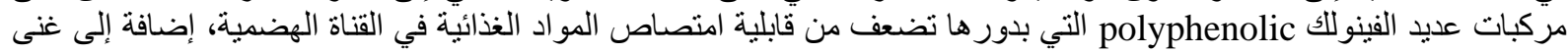

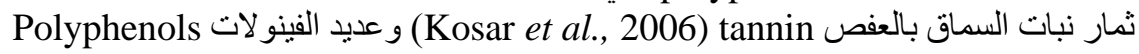

(Özcan and Haciseferogullari, 2004; Gönül et al., 2010)

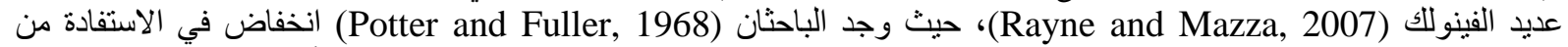

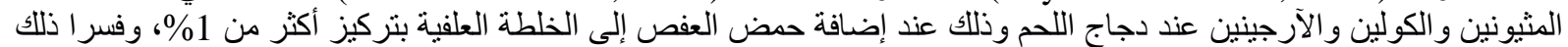

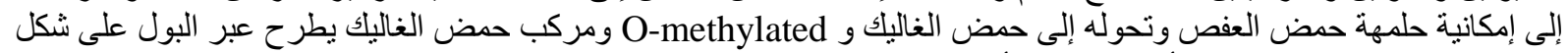
4- O-methyl gallic acid المثيونين و الكولين (Potter and Fuller, 1968)، علاوة على ذلك يعرف بأن العفص يخفض من قابلية الاستفادة من البروتين من الفن 


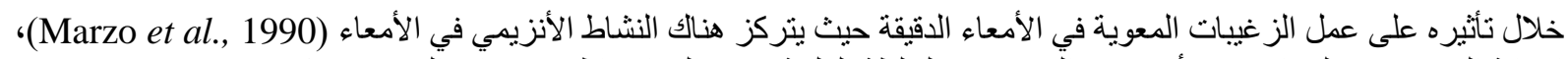

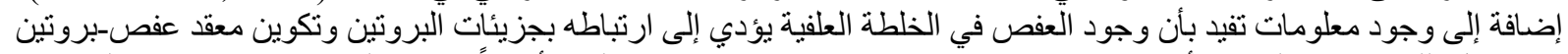

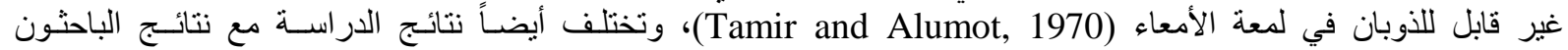
(Alishah et al., 2013)

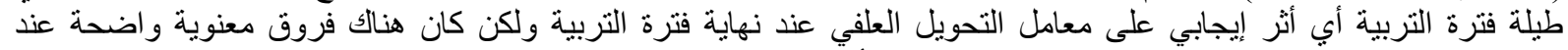

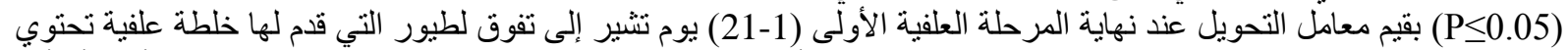

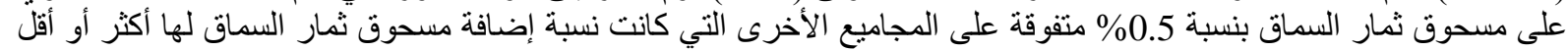
من هذه النسبة، في حين لم يكن هناك فروق تذكر عند نهاية فنرة التربية.

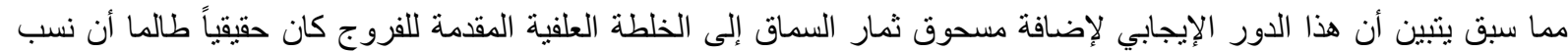

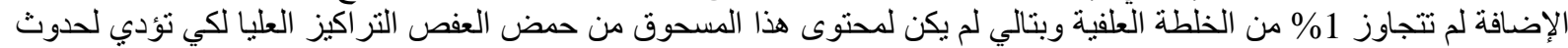

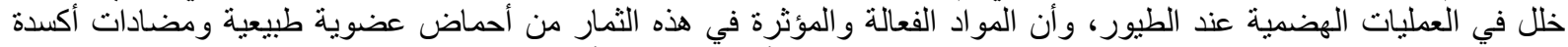
طبيعة كان لها دور ها في كبح نثاط الجراثيم غير النافعة في لمعة الأمعاء وتحسين أداء الجهاز الهضئ الهي الهي بشكل خاص.

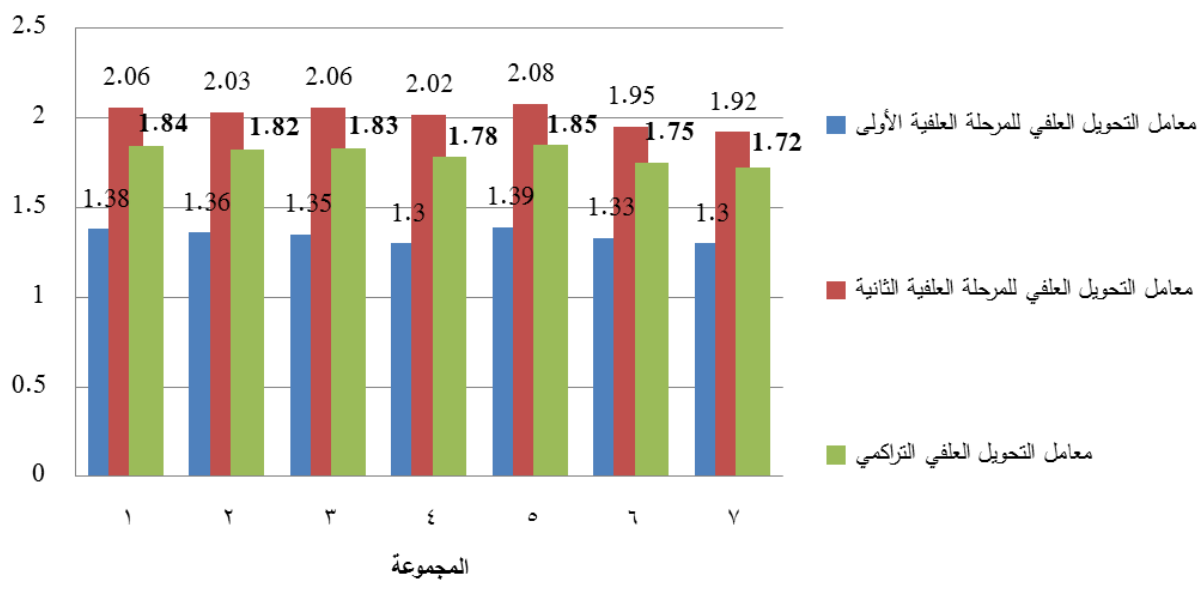

مخطط رقم (7) : معامل التحويل العلفي للمر احل العلفية الأولى والثانية و التر اكمي لطيور الهجموعات السبعة المدروسة

جدول رقم (5): معامل التحويل العلفي الأسبوعي و التر اكمي لطيور المجموعات السبعة المدروسة

\begin{tabular}{|c|c|c|c|c|c|c|c|}
\hline المجمو عة (V) & المجمو عة (ך) & المجمو عة (0) & المجمو عة (ع) & المجمو عة (r) & المجمو عة (Y) & المجمو عة (1) & المجمو عات \\
\hline بذرة ب0\% بذون & بذرة 0.4 بماق بدون & بذرة 0.2 بداق \%بون & كاملة سماق حبة \%0.6 & كاملة 0.4 مبةق & كاملة 0.2 سماق حبة & الثـاهد & العمر (أسبوع) \\
\hline 1.17 & 1.01 & 1.21 & 1.20 & 1.15 & 1.19 & 1.14 & الأول \\
\hline 1.20 & 1.27 & 1.30 & 1.24 & 1.21 & 1.43 & 1.41 & الثانى \\
\hline 1.39 & 1.44 & 1.48 & 1.35 & 1.48 & 1.36 & 1.44 & الثالث \\
\hline 1.71 & 1.74 & 1.83 & 1.74 & 1.82 & 1.86 & 1.87 & الرابع \\
\hline 1.89 & 1.88 & 1.97 & 1.89 & 1.97 & 1.96 & 2.07 & الخامس \\
\hline 2.20 & 2.23 & 2.50 & 2.46 & 2.24 & 2.27 & 2.25 & السادس \\
\hline 1.72 & 1.75 & 1.85 & 1.78 & 1.83 & 1.82 & 1.84 & التراكمى \\
\hline
\end{tabular}

CONCLUSIONS AND RECOMMENDATION

الاستتتاجات والتوصيات

ا. أدى إضافة مسحوق ثمار نبات السماق إلى تحسين الوزن الحي وكان هناك تتاسب طردي بين نسب الإضافة وتحسن الوزن الحئ الحي

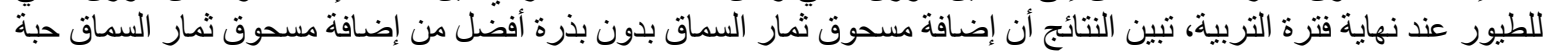

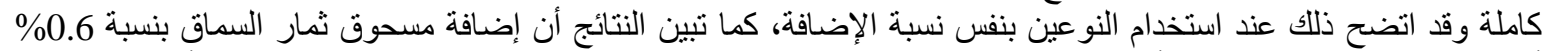
أفضل من إضافته بنسبة 0.2\% أو 0.4\% وذلك بغض النظر عن نو عه سواء كان مسحوق ثمار السماق حبة كاملة أو بدون بذرة 


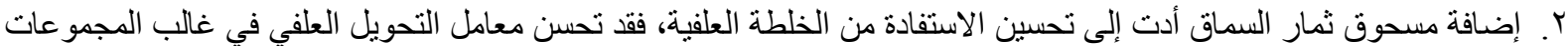

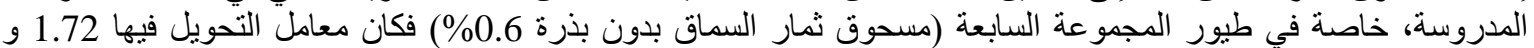

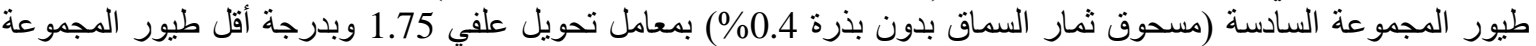

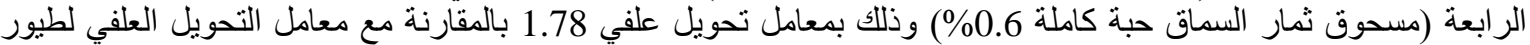
مجمو عة الثاهد الذي كان 1.84.

r. نوصي بإضافة مسحوق ثمار السماق بذون بذرة إلى الخلطة العلفية المقدمة للفروج بنسبة 0.6\%، لما لهذه الإضافة من أثر إيجابي واضح على الوزن الحي.

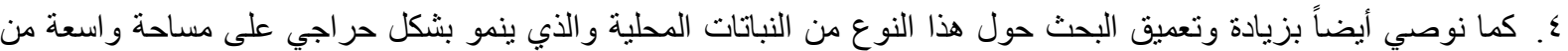

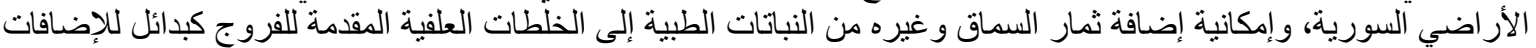

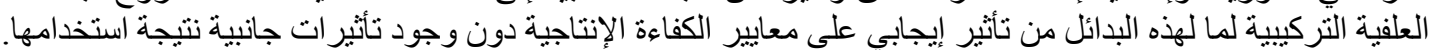

\section{REFERENCES}

المراجع

Alishah, A.; Daneshyar, M. and Aghazadeh, A. (2013): The effect of dietary sumac fruit powder (Rhus coriaria L.) on performance and blood antioxidant status of broiler chickens under continuous heat stress condition. Italian Journal of Animal Science 2013; 12:e6. doi:10.4081/ijas.2013.e6.

Attari, A.M.; Amin, G.H.; Fazeliand, M.R. and Jamalifar, H. (2007): Medicinal Plants. 7(1): 1-9.

Blanchard, P. and Wright, F. (2000): Less buffering...more enzymes and organic acids. Pig Progr.2000; 16(3): 23-25.

Diarra, S. and François Malouin (2014): Antibiotics in Canadian poultry productions and anticipated alternatives. frontiers in Microbiology published: 17 June 2014 doi: 10.3389/fmicb.2014. 00282.

Endts, H.P.; Rujis, G.H. and Van Klingeren, B. (1991): Quinolon resistance in Campylobacter isolated from man and poultry following the introduction fluroquinolones in veterinary medicine. $\mathrm{J}$. Antimicrob. Chemother. 27: 199-208.

Golzadeh, M.; Farhoomand, P. and Daneshyar, M. (2012): Dietary Rhus coriaria L. powder reduces the blood cholesterol, VLDL-c and glucose, but increases abdominal fat in broilers. South African Journal of Animal Science 2012, 42 (No. 4).

Gönül, A. and Karapinar, M. (2010): Efficacy of sumac and oregano in the inactivation of Salmonella typhimurium on tomatoes. Int. J. Food. Microbiol. 141, 39-44.

Greathead, H. (2003): Plants and plant extracts for improving animal productivity Proc. Nutr. Soc. 62: 279-290.

Kosar, M.; Bozan, B.; Temelli, F. and Baser, K.H.C. (2006): Antioxidant activity and phenolic composition of sumac (Rhus coriaria L.) extracts. Food. Chem.103, 952-959.

Levy, S.W. (1997): Antibiotic resistance: an ecological imbalance. in: Chadwick I. and Goode, J. (eds). Antibiotic resistance: origins, evolution, selection and spread: Chichester, Ciba Foundition Symposium, pp.1-14.59.

Mansoub, N. (2011): Effect of different levels of Sumac Powder (Rhus Coriaria L.) on performance, carcass and blood parameters of broiler Chickens. Annals of Biological Research, 2011,2(5):647-652 (http://scholarsresearchlibrary.com/archive.html).

Marzo, F.; Tosar, A. and Santidrian, S. (1990): Effect of tannic acid on the immune response of growing chickens. J. Anim. Sci. 40, 1189-1197.

Maulyanov, S.M.; Islambekov, S.Y.; Karimdzhanov, A.K. and Ismaikov, A.I. (1997): Chem. Nat. Comp. 33, 209 (1997).

Mead and Griffin (1998): Escherichia Coli O157:H7. Lancet 352, 1207-12.

NRC (1994): Nutrient requirements of poultry. 9th rev. ed. Natl. Acad. Press, Washington, DC.

Özcan, M. and Haciseferogullari, H. (2004): A condiment sumac (Rhus coriaria L.) fruits: Properties. Bulg. J. Plant. Physiol. 30, 74-84.

Potter, D.K. and Fuller, H.L. (1968): Metabolic fate of dietary tannins in chickens. J. Nutr. 96, 187191.

Pourreza, J. and Sadeghi, G.H. (2008): Management of poultry production. Nasher Ardakan Press. Isfahan, Iran. pp: 412-12. 
Rayne, S. and Mazza, G. (2007): Biological activities of extracts from sumac (Rhus spp.): a review. Plant. Food. Hum. Nutr. 62, 165-175.

Sagdic, O.; Kussu, A.; Ozcan, M. and Ozcelik, S. (2003): Effect of turkey spice extracts at various concentrations on the growth of E.Cole O157:H7.Food protection, 19,473-480.

SPSS (2008): SPSS 17.0.1 for Window by SPSS Inc.

Tamir, M. and Alumot, E. (1970): Carob tannins-growth depression and levels of insolubile nitrogen in the digestive tract of rats. J. Nutr. 100, 573-580.

Witte, W. (1998): Medical consequences of antibiotic use in agriculture. science. (1998), 279(5353): 996-997.

World Health Organization meeting (1997): The medical impact of the use of antimicrobial in food animals. Report of W.H.O. meeting. Berlin, Germany, 17.

Wray, C. and Davies, R.H. (2000): Competitive exclusion-an alternative to antibiotics. Vet. J., 159: 107-108. 